\title{
Decreased Levels of VAMP2 and Monomeric Alpha-Synuclein Correlate with Duration of Dementia
}

Julie Vallortigara ${ }^{1}$, David Whitfield ${ }^{1}$, William Quelch ${ }^{1}$, Amani Alghamdi ${ }^{1}$, David Howlett ${ }^{1}$, Tibor Hortobágyi ${ }^{2}$, Mary Johnson ${ }^{3}$, Johannes Attems ${ }^{3}$, John T. O’Brien ${ }^{3,4}$, Alan Thomas ${ }^{3}$, Clive G. Ballard ${ }^{1}$, Dag Aarsland ${ }^{5,6}$, Paul T. Francis ${ }^{1}$

${ }^{1}$ Wolfson Centre for Age-Related Diseases, Institute of Psychiatry, Psychology and Neuroscience, King's College London, London, UK

${ }^{2}$ Division of Neuropathology, Institute of Pathology, Faculty of Medicine, University of

Debrecen, Debrecen, Hungary

${ }^{3}$ Institute of Neuroscience, Newcastle University, CAV, Newcastle upon Tyne, UK

${ }^{4}$ Department of Psychiatry, University of Cambridge, Cambridge, UK

${ }^{5}$ Department of Neurobiology, Ward Sciences and Society, Karolinska Institute, Stockholm, Sweden

${ }^{6}$ Centre for Age-Related Medicine, Stavanger University Hospital, Stavanger, Norway

Running title: VAMP2 correlates to duration of dementia Accepted 8 October 2015

*Correspondence to: Dr. David Whitfield, Wolfson Centre for Age Related Diseases, King's College London, SE1 1UL, UK. Tel.: +44 02078486910; E-mail: david.r.whitfield@kcl.ac.uk 


\section{ABSTRACT}

Alpha-synuclein ( $\alpha$-syn) aggregations are the key pathological hallmark of dementia with Lewy bodies (DLB) and Parkinson's disease dementia (PDD), but are also frequently present in Alzheimer's disease (AD). Much remains unknown about the role of $\alpha$-syn in the synapse and the wider role of synaptic dysfunction in these dementias. Changes in concentrations of key 'SNAP (Soluble N-ethylmaleimide Sensitive Factor Attachment Protein) Receptor' (SNARE) proteins as a consequence of alterations in the aggregation state of $\alpha$-syn may contribute to synaptic dysfunction in patients with DLB, PDD, and AD and result in impaired cognition. We have studied a large cohort $(\mathrm{n}=130)$ of autopsy confirmed DLB, PDD, AD, and control brains. Using semi-quantitative western blotting, we have demonstrated significant changes across the diagnostic groups of DLB, PDD, and AD in the SNARE and vesicle proteins syntaxin, Munc18, VAMP2, and monomeric $\alpha$-syn in the prefrontal cortex, with a significant reduction of Munc 18 in AD patients $(p<0.001)$. This correlated to the final MMSE score before death $(p=0.016)$. We also identified a significant negative correlation between the duration of dementia and the levels of the binding partners VAMP2 $(\mathrm{p}=0.0004)$ and monomeric $\alpha$-syn $(\mathrm{p}=0.0002)$. Our findings may indicate that an upregulation of SNARE complex related proteins occurs in the early stages of disease as an attempt at compensating for failing synapses, prior to widespread deposition of pathological $\alpha$-syn.

Keywords: alpha-synuclein, Alzheimer's disease, dementia with Lewy bodies, Munc18, Parkinson's disease dementia, SNARE process, synaptic dysfunction, VAMP2 


\section{INTRODUCTION}

Dementia is defined as progressive cognitive decline of sufficient magnitude to interfere with normal social or occupational function. Alzheimer's disease (AD) and the Lewy body dementias (LBD), incorporating dementia with Lewy bodies (DLB) and Parkinson's disease dementia (PDD), collectively comprise over $70 \%$ of all dementia diagnoses

(http://www.alzheimers.org.uk). LBD is pathologically characterized by $\alpha$-synuclein ( $\alpha$-syn), with varying amounts of amyloid- $\beta$ protein $(A \beta)$ and hyperphosphorylated microtubule associated protein tau (tau) aggregates in addition to synaptic loss [1]. Clinical hallmarks include fluctuating and deteriorating cognition, hallucinations, and parkinsonism $[2,3]$. AD is characterized by $\mathrm{A} \beta$ and tau aggregates and gradual worsening of cognition, in particular episodic memory and executive function $[4,5]$.

$\alpha$-Syn, first identified as the main component of Lewy bodies (LBs) [6] — and thus the key pathological protein of DLB and PDD — is, under physiological conditions, located in the presynaptic terminal. Kramer and Schulz-Schaeffer [7] reported accumulation of small aggregates of $\alpha$-syn at the synapses of DLB postmortem brains. These aggregates were proposed to interfere with synaptic function. The authors also suggested that the formation of small aggregates of $\alpha$-syn was a direct precursor to the development of LBs, and possibly represented a final cytoprotective attempt before cell death. Thus, focus on the events occurring at the synapse in advance of LB formation could be of greater potential therapeutic benefit. This is of relevance not just to the established synucleinopathies such as DLB and PDD but also AD. It is now recognized that a proportion of sporadic $\mathrm{AD}$ cases present with LBs; this has been reported to be as high as $51 \%$ [8], and is particularly observed within the amygdala where LBs are often colocalized with neurofibrillary tangles [9-11]. 
Some of the mutations in the $S N C A$ gene known to give rise to $\alpha$-syn disorders exert their pathogenic effect through promotion of aggregation or oligomerization of $\alpha$-syn [12]. In addition to involvement in pathogenic mechanisms, there has been increasing focus on the physiological role of $\alpha$-syn. Current understanding indicates that $\alpha$-syn plays a role in neurotransmitter release, synaptic plasticity, and pre-synaptic vesicle pool size [13-15]. More particularly it is thought that monomeric $\alpha$-syn drives formation of the SNARE complex through a chaperone-like activity involving binding to phospholipids and VAMP2 (vesicle-associated membrane protein 2, or synaptobrevin-2) [16]. SNARE is an acronym for 'SNAP (Soluble N-ethylmaleimide Sensitive Factor Attachment Protein) Receptor'. SNARE proteins play a key role in neurotransmittercontaining vesicle fusion to the presynaptic membrane thereby modulating neurotransmitter release [17]. Interestingly, it was recently reported that large $\alpha$-syn oligomers bind preferentially to VAMP2 (vesicle-associated membrane protein 2), resulting in inhibition of docking between donor and acceptor vesicles [18]. Thus it is plausible that VAMP2 could represent a key component for mediating the impact of $\alpha$-syn.

VAMP2 and syntaxin 1, both members of the SNARE protein family, are respectively localized to synaptic vesicles and the presynaptic membrane where they form part of the SNARE complex required for vesicle release (see Figure 1) [17]. Munc18 binds to syntaxin 1, and is thought to assist in the first steps of SNARE assembly, as well as playing a role in later stages of the exocytosis [19-21]. Reductions in SNARE proteins have been previously reported in LBD and AD. Specifically, it was found that levels of synaptophysin, syntaxin, and SNAP25 were decreased in individuals with DLB in the visual areas (BA17 and BA18/19) [22]. Furthermore, we have reported reductions of dynamin1, a regulator of synaptic vesicle recycling, to be associated with cognitive decline in LBD [23]. It has also been demonstrated that the same 
SNARE proteins can be elevated in AD during the mild stages of dementia, but decline as the severity of disease develops [24]. It would appear that synaptic changes can vary by neocortical region and pathology. Thus, it is apparent that much about the synaptic changes in AD and LBD remains to be elucidated.

This study aims to aid our understanding of the synaptic dysfunction that occurs in LBD and $\mathrm{AD}$ by providing a characterization of changes in key markers of the synapse machinery and any relationships to other aspects of the disease. We therefore determined the expression of the presynaptic proteins $\alpha$-syn, VAMP2, syntaxin1A, Munc18, and the ubiquitous synaptic marker synaptophysin (SPP) and investigated the relationships between these proteins and clinical and pathological hallmarks of the disease.

\section{MATERIALS AND METHODS}

\section{Participants, diagnosis, and assessment}

Table 1 shows the demographic details of the patients and controls. Postmortem brain tissue was kindly supplied by the following Brains for Dementia Research Network brain banks: the MRC London Neurodegenerative Diseases Brain Bank, the Thomas Willis Oxford Brain Collection and the Newcastle Brain Tissue Resource, and from the University Hospital Stavanger (Norway). Informed consent was obtained for all tissue to be used in research and the study had ethics approval (08/H1010/4). Prefrontal cortex (Brodmann area, BA9) was used for all biochemical and histopathological analysis. BA9 was selected due to its proposed role in executive function and cognition [25], decline of which is a cardinal symptom of DLB and PDD, Neuropathological assessment was performed according to standardized neuropathological scoring/grading systems, including Braak staging, Consortium to Establish a Registry for 
Alzheimer's Disease (CERAD) scores, Newcastle/ McKeith Criteria for LBD, National Institute on Aging-Alzheimer's Association (NIA-AA) guidelines and phases of amyloid- $\beta$ (A $\beta$ ) deposition (A $\beta$-phases) [2, 26-29]. Controls were neurologically normal, with only mild age associated neuropathological changes (e.g., neurofibrillary tangle Braak stage $\leq$ II) and no history of neurological or psychiatric disease.

Cognitive impairment data consisted of the last Mini-Mental State Examination (MMSE) scores a maximum of two years prior to death [30]. Patients and controls were categorized as previously described [31]. Final diagnoses for patients are clinico-pathological consensus diagnoses incorporating the one-year rule to differentiate DLB and PDD [2].

\section{Immunohistochemistry}

Semi-quantitative assessments of $A \beta$, tau and $\alpha$-syn pathology were conducted as in our previous study [32] blind to clinical diagnosis, by neuropathologists, using a scale of 0 (none), 1 (sparse), 2 (moderate), and 3 (severe/frequent) to score sections from BA9, BA24, and BA40. For detection of senile $\mathrm{A} \beta$ plaques, sections were stained with an anti-A $\beta$ 1E8 or $4 \mathrm{G} 8$ antibody at 1:1000. Tau immunohistochemistry (AT8 antibody (Innogenetics) at 1:200) and silver impregnation (Gallyas or modified Bielschowsky) were used to detect neurofibrillary tangles,

neuritic plaques, dystrophic neurites, and neuropil threads. $\alpha$-syn pathology was detected using NCL-SYN antibody (Novocastra Laboratories) at 1:200.

\section{Preparation of tissue samples for western blotting}

Preparation of tissue for western blotting was as previously described [33]. Briefly, grey matter was isolated from the tissue and homogenized in ice cold buffer containing $50 \mathrm{mM}$ tris- 
HCL, 5 mM EGTA, 10 mM EDTA, 'complete protease inhibitor cocktail tablets' (Roche, 1 tablet per $50 \mathrm{ml}$ of buffer), and $2 \mu \mathrm{g} / \mathrm{ml}$ pepstatin A dissolved in ethanol:DMSO 2:1 (Sigma). Buffer was used at a ratio of $2 \mathrm{ml}$ to every $100 \mathrm{mg}$ of tissue and homogenization performed using an IKA Ultra-Turrax mechanical probe (KIA Werke, Germany) until the liquid appeared homogenous.

Protein concentration was established using the Coomassie (Bradford) Protein Assay Kit (Thermo Scientific); $10 \mu \mathrm{l}$ of crude homogenate was diluted 1:50 and read in triplicate at $595 \mathrm{~nm}$ using a FlexStation 3 (Molecular Devices). A BSA standard curve run at the same time as the samples was used to calculate the concentration.

\section{Western blotting}

Crude brain homogenate was diluted 4:5 with 5x sample buffer (Genscript MB01015), boiled for $5 \mathrm{~min}$ then stored at $-20^{\circ} \mathrm{C}$. Samples were loaded at $20 \mu \mathrm{g} / \mathrm{ml}$ total protein on $10 \% \mathrm{SDS}$ polyacrylamide gel for protein separation, transferred to nitrocellulose membrane (Hydrobond-C, Amersham), and probed with either anti-Syntaxin1 (abcam ab24731, 1:20000), anti-Munc18 (abcam ab75042, 1:2000), anti-VAMP2 (abcam ab70222, 1:10000), anti-alpha-synuclein monomeric (BD Transduction Laboratories 610787, 1:20000) or anti-synaptophysin (abcam ab8049, 1:10000), and the relevant secondary antibody (IRDye from LI-COR). Bands were detected using an Odyssey infrared fluorescent scanner, and in all cases a single band was observed at the correct molecular weight (see Figure 2). The integral of intensity was quantified using Odyssey infrared imaging systems application software version 3.0.16 and expressed as ratios to rat cortex in arbitrary units. The same rat cortex was used for all membranes to provide an inter-membrane control. Samples were loaded randomly so that samples from different 
diagnostic groups were run together. We did not use a loading control as we have previously shown changes in the levels of beta-III-tubulin, a standard loading control, between diagnostic groups, and unpublished data for histone 3 showed similar variation [31]. Given the context of severe neurodegeneration and end stage pathology this is unsurprising and explains our decision not to use a loading control.

\section{Statistical analysis}

Statistical analysis of the biochemical data was undertaken as described previously [31, 34]; briefly synaptophysin values were significantly predicted by the years in storage and so a residual variable was created for this protein to statistically remove this effect. This variable was then normalized using a $\log 10$ transformation. Munc18 and VAMP2 ratio values were normalized using a square root transformation. Syntaxin1 and monomeric $\alpha$-syn ratio values were normalized using a $\log E$ transformation. VAMP2 and monomeric $\alpha$-syn ratio values were significantly predicted by age at death and so residual variables were created to compensate for this effect. VAMP2 ratio values were then normalized again using LogE.

\section{RESULTS}

Synaptophysin (SPP) levels were significantly reduced in PDD cases compared to all other diagnostic groups but there was no significant difference between the levels of synaptophysin in control, AD, or DLB cases (data not shown). As Munc18, syntaxin1, VAMP2, and monomeric $\alpha$-syn are all synaptic proteins and we observed the aforementioned decrease in synapses, it was decided to express these proteins as ratios to the synaptophysin value, case by case. This 
established approach allows the actual change in these proteins to be removed from any general effect of a change in synapses $[35,36]$.

With regards to the Munc18:synaptophysin ratio; there was a reduction in AD cases of $33 \%$ compared to DLB cases, 26\% compared to PDD, and 25\% compared to control cases (Figure 1A). The significant changes in the syntaxin 1 :synaptophysin ratio were an increase of $28 \%$ in AD cases compared to PDD cases and 34\% compared to control cases (Figure 1B). The ratio of VAMP2 to synaptophysin was significantly higher in PDD cases compared to controls by $16 \%$, to DLB cases by $23 \%$, and to AD cases by $65 \%$. Furthermore, the ratio of VAMP 2 to synaptophysin was significantly lower in AD cases compared to DLB cases by $34 \%$ and compared to controls, by $42 \%$ (Figure 1C). The ratio of monomeric $\alpha$-syn to synaptophysin was significantly higher in PDD cases compared to controls, by $25 \%$ and to AD cases by $53 \%$. Furthermore, it was significantly lower in AD cases compared to DLB cases by $38 \%$ and compared to controls, by $22 \%$ (Figure 1D).

Linear regression analysis showed the years of dementia to have a highly significant negative correlation with the ratios of VAMP2 to synaptophysin (Figure 3A) and monomeric $\alpha$-syn to synaptophysin (Figure 4A) in the prefrontal cortex. Likewise, a significant positive correlation was found between years of parkinsonism and both the ratio of VAMP2 to synaptophysin (Figure 3B) and the ratio of monomeric a-syn to synaptophysin (Figure 4B) in the prefrontal cortex. Both of these analyses included all individuals with AD, DLB, and PDD, for whom data on the duration of dementia was available, but not controls. The $\mathrm{n}$ values for years of dementia for both VAMP2:SPP and $\alpha$-syn:SPP were: PDD $n=18, \mathrm{DLB}=23$, and $\mathrm{AD}=15$. For years of parkinsonism, they were: PDD $n=18$, DLB $n=20$, and $A D n=15$. 
We undertook further analysis to determine whether these correlations with the ratios of either VAMP2 or monomeric $\alpha$-syn to years of dementia or parkinsonism were driven by values from particular diagnostic groups. When separating cases by clinical diagnosis, the only significant correlation remaining was between monomeric $\alpha$-syn in PDD cases and the years of dementia (Pearson's $r=-0.562, \mathrm{p}=0.015 \mathrm{n}=18$ ).

The ratio of Munc18 to synaptophysin correlated with the last MMSE score prior to death (Pearson's $\mathrm{r}=0.282, \mathrm{p}=0.016, \mathrm{n}=73$ ); the distribution and other details of the MMSE scores for this cohort have been reported previously [31]. There was no correlation between MMSE scores (the last score prior to death or the decline per year) and any of the other protein ratios $(\mathrm{p}>0.05)$. There was also no correlation between any of the protein ratios and the semi-quantitative pathology scores for $A \beta$, tau, or $\alpha$-syn ( $\mathrm{p}>0.05)$.

Figure 5 shows the percentage of cases of each of the diagnostic groups that fall into each category of pathological score. In particular, it serves to highlight the difference in spread of $\alpha$ syn pathology between the PDD and DLB cases, with far fewer PDD cases in the moderate and severe categories relative to the DLB cases.

\section{DISCUSSION}

We report that a longer duration of dementia was strongly association with a decrease in levels of both VAMP2 and monomeric $\alpha$-syn. Furthermore VAMP2 and monomeric $\alpha$-syn appeared to be upregulated in PDD cases, cases that in general had low levels of $\alpha$-syn pathology compared to the DLB cases. This may indicate that an upregulation of SNARE process-related proteins occurs in the early stages of dementia as an attempt to compensate for failing synapses, prior to widespread deposition of pathological $\alpha$-syn. 
$\alpha$-syn aggregation is the pathological hallmark of DLB and PDD, appearing as LBs and neurites throughout the cortex, but is also present in many people with AD. While evidence is emerging of the physiological roles of monomeric $\alpha$-syn in SNARE complex processes, less is known about the intermediate steps that lie between this physiological role and the final pathological deposition seen in the end-stages of disease. We saw a strikingly similar pattern of change between VAMP2 and monomeric alpha-synuclein, which is not surprising given that the two proteins are binding partners [16].

A benefit of expressing the biochemical data as a ratio to synaptophysin is that this provides an index to the number of synaptic terminals and helps account for changes in synapse density that may cloud changes to specific synaptic proteins. Importantly, the results were not substantially different when this ratio was not used (data not shown). We therefore conclude that there was a specific loss of SNARE proteins in addition to a more general loss of synapses. This was particularly relevant to PDD cases that were characterized by lower SPP levels.

The accumulation of $\alpha$-syn and SNARE proteins at synaptic nerve terminals in transgenic mice and in Parkinson's disease, in conjunction with impaired dopamine release in both transgenic mouse brain and transfected PC12 cells, is suggested by Garcia-Reitbock and colleagues to indicate a gain of toxic function of $\alpha$-syn at the synapse [37]. This is consistent with previous findings in transfected cells, which showed that overexpression of $\alpha$-syn inhibits evoked neurotransmitter release by acting at a step between vesicle docking and fusion [38]. It could be that a balance between monomeric $\alpha$-syn and SNARE proteins is necessary for proper SNARE assembly and function; alternatively, it could be that an increase in $\alpha$-syn causes the formation of toxic oligomers that affect SNARE distribution and function. This causes a problem as an oligomer of $\alpha$-syn can bind to many VAMP2 proteins on several different vesicles causing 
vesicle clustering [18]. By clustering around oligomeric $\alpha$-syn, vesicles cannot dock at the presynaptic terminal and therefore exocytosis of neurotransmitter cannot occur.

Here we observed a combination of increases in both monomeric $\alpha$-syn and VAMP2 in PDD cases. A recent study reported increased expression of VAMP2 protein accompanied increased $\alpha$-syn expression in the striatum of Snap25S187A/S187A mice [39]. These mice displayed a significant age-dependent change in the distribution of $\alpha$-syn and its Ser129-phosphorylated form in hypertrophied glutamatergic nerve terminals in the striatum. Knowing that the binding of the $\mathrm{C}$ terminus of $\alpha$-syn to the $\mathrm{N}$ terminus of VAMP2 primes the subsequent SNARE complex assembly [40], the increase in VAMP2 level might also reflect a compensatory response to the impaired synaptic vesicle release by enhancing SNARE complex formation in concert with the increased $\alpha$-syn [39]. This increase in VAMP2 and monomeric $\alpha$-syn could also relate to the inherent differences between PDD and the other dementias, such as the typically long period of parkinsonism prior to development of dementia, or to the relative lack of AD-related pathology. The positive correlation between MMSE prior to death and the ratio of Munc18 to synaptophysin underlines the importance of intact synaptic machinery to cognition. That we did not see correlations with the other proteins is probably due to the prefrontal cortex not being a key region for memory - having a stronger role in executive function, a domain the MMSE is poor at detecting [2]. We have previously shown that $\alpha$-syn pathology in BA21 is associated with cognitive decline as assessed by the MMSE [32], and so it would be interesting to examine these SNARE proteins in this region to determine if monomeric $\alpha$-syn shows a similar relationship to pathological $\alpha$-syn.

In the present study, we found that a concomitant deregulation of SNARE proteins and monomeric $\alpha$-syn was strongly associated with the duration of dementia. It has been suggested 
that this process could represent an initial pathological event in DLB, eventually leading to the death and degeneration of neuronal cells [41]. The correlation we report between monomeric $\alpha$ syn and duration of dementia suggests this hypothesis may also apply to PDD. Alterations in syntaxin1 and other SNARE proteins have been previously reported in AD and DLB [21, 22, 42, 43]; Minger et al. only found a decrease in these proteins in the oldest dementia cases and the Mukaetova-Ladinska studies did not separate PDD and DLB. The toxicity of $\alpha$-syn, in sporadic and familial disease, has been proposed to arise in several ways; through inhibition of histone acetylation, perforation of membranes and the consequent disruption of ionic balance, and finally neuronal death via the inhibition of a neuronal survival factor MEF2D [44]. Beyer et al. suggest that in fact there maybe multiple pathways involving $\alpha$-syn and other proteins linked to LBs that culminate in the same end-stage pathology of LBs and neurites.

Some limitations of this study include those that are inherent to all investigations using human postmortem tissue, in that we are restricted to providing observations and correlations of changes in what is for the most part late-stage disease. Nonetheless, it is vital to have a comprehensive characterization of these changes if better cell and animal models are to be designed that are more able to recapitulate the multiple processes underlying synaptic dysfunction and dementia.

Targeting the toxicity of $\alpha$-syn at the synapse, and its connection with SNARE proteins, could be an effective way to tackle the pathology and the progression of the disease at an early stage. Further functional studies are warranted to provide insight into the chronology of the relationship between VAMP2 and monomeric $\alpha$-syn: are changes in VAMP2 driving a loss of monomeric $\alpha$-syn to other forms of $\alpha$-syn? Or is the loss of monomeric $\alpha$-syn impacting VAMP2, SNARE machinery, and ultimately synaptic function? Finally, development of imaging 
ligands or an assay for cerebrospinal fluid detection of VAMP2 or monomeric $\alpha$-syn would be of great interest given the predictive association we show between duration of dementia and parkinsonism, and these proteins.

\section{ACKNOWLEDGMENTS}

The main funding was provided by the Alzheimer's Society UK and the BUPA Foundation. The research in Newcastle was supported in part by the Dunhill Medical Trust (R173/1110). Tissue for this study was provided by (i) the Newcastle Brain Tissue Resource; (ii) the London Neurodegenerative Brain Bank; and (iii) the Thomas Willis Oxford Brain Collection. All three resources are funded in part by grants from the UK Medical Research Council and by Brains for Dementia Research, a joint venture between Alzheimer's Society and Alzheimer's Research UK. Professor Margaret Esiri and Drs. Olaf Ansorge, Safa Al-Sarraj, Istvan Bodi, and Andrew King are thanked for neuropathological diagnosis of cases. Dr. Claire Troakes at the MRC London Neurodegenerative Diseases Brain Bank is thanked for supplying tissue sections. The authors express their thanks to all the donors and brain banks for the tissue used in this study. This Newcastle Brain Tissue Resource is supported by the National Institute for Health Research (NIHR) Newcastle Biomedical Research Unit based at Newcastle upon Tyne Hospitals NHS Foundation Trust and Newcastle University and the Medical Research Council and Brains for Dementia Research. The MRC London Neurodegenerative Diseases Brain Bank is funded by the Medical Research Council and Brains for Dementia Research. TH has received salary support from the Hungarian Brain Research Programme Grant No. KTIA_13_NAP-A-II/7. CB would like to thank the National Institute for Health Research (NIHR) Mental Health Biomedical Research Centre and Dementia Unit at South London and Maudsley NHS Foundation Trust and 
[Institute of psychiatry] King's College London. This article presents independent research supported/funded by the National Institute for Health Research (NIHR). The views expressed are those of the authors and not necessarily those of the NHS, the NIHR or the Department of Health.

Authors' disclosures available online (http://j-alz.com/manuscript-disclosures/15-0707r1). 


\section{REFERENCES}

[1] Dickson DW (2002) Dementia with Lewy bodies: neuropathology. J Geriatr Psychiatry Neurol 15, 210-216.

[2] McKeith IG, Dickson DW, Lowe J, Emre M, O'Brien JT, Feldman H, Cummings J, Duda JE, Lippa C, Perry EK, Aarsland D, Arai H, Ballard CG, Boeve B, Burn DJ, Costa D, Del ST, Dubois B, Galasko D, Gauthier S, Goetz CG, Gomez-Tortosa E, Halliday G, Hansen LA, Hardy J, Iwatsubo T, Kalaria RN, Kaufer D, Kenny RA, Korczyn A, Kosaka K, Lee VM, Lees A, Litvan I, Londos E, Lopez OL, Minoshima S, Mizuno Y, Molina JA, Mukaetova-Ladinska EB, Pasquier F, Perry RH, Schulz JB, Trojanowski JQ, Yamada M (2005) Diagnosis and management of dementia with Lewy bodies: third report of the DLB Consortium. Neurology 65, 1863-1872.

[3] Aarsland D, Rongve A, Nore SP, Skogseth R, Skulstad S, Ehrt U, Hoprekstad D, Ballard C (2008) Frequency and case identification of dementia with Lewy bodies using the revised consensus criteria. Dement.Geriatr.Cogn Disord. 26, 445-452.

[4] Ballard C, Gauthier S, Corbett A, Brayne C, Aarsland D, Jones E (2011) Alzheimer's disease. Lancet 377, 1019-1031.

[5] McKhann GM, Knopman DS, Chertkow H, Hyman BT, Jack CR, Kawas CH, Klunk WE, Koroshetz WJ, Manly JJ, Mayeux R, Mohs RC, Morris JC, Rossor MN, Scheltens P, Carrillo MC, Thies B, Weintraub S, Phelps CH (2011) The diagnosis of dementia due to Alzheimer's disease: recommendations from the National Institute on Aging-Alzheimer's Association workgroups on diagnostic guidelines for Alzheimer's disease. Alzheimers Dement 7, 263-269.

[6] Spillantini MG, Schmidt ML, Lee VM, Trojanowski JQ, Jakes R, Goedert M (1997) Alpha-synuclein in Lewy bodies. Nature 388, 839-840.

[7] Kramer ML, Schulz-Schaeffer WJ (2007) Presynaptic \{alpha\}-Synuclein Aggregates, Not Lewy Bodies, Cause Neurodegeneration in Dementia with Lewy Bodies. Journal of Neuroscience 27, 1405-1410.

[8] Jellinger KA (2003) Alpha-synuclein pathology in Parkinson's and Alzheimer's disease brain: incidence and topographic distribution--a pilot study. Acta Neuropathol 106, 191-201.

[9] Fujishiro H, Tsuboi Y, Lin WL, Uchikado H, Dickson DW (2008) Co-localization of tau and alphasynuclein in the olfactory bulb in Alzheimer's disease with amygdala Lewy bodies. Acta Neuropathol 116, 17-24.

[10] Uchikado H, Lin WL, DeLucia MW, Dickson DW (2006) Alzheimer disease with amygdala Lewy bodies: a distinct form of alpha-synucleinopathy. J Neuropathol Exp Neurol 65, 685-697.

[11] Schmidt ML, Martin JA, Lee VM, Trojanowski JQ (1996) Convergence of Lewy bodies and neurofibrillary tangles in amygdala neurons of Alzheimer's disease and Lewy body disorders. Acta Neuropathol 91, 475-481.

[12] Brown DR (2010) Oligomeric alpha-synuclein and its role in neuronal death. IUBMB Life 62, 334339.

[13] Abeliovich A, Schmitz Y, Fariñas I, Choi-Lundberg D, Ho WH, Castillo PE, Shinsky N, Verdugo JM, Armanini M, Ryan A, Hynes M, Phillips H, Sulzer D, Rosenthal A (2000) Mice lacking alphasynuclein display functional deficits in the nigrostriatal dopamine system. Neuron 25, 239-252.

[14] Murphy DD, Rueter SM, Trojanowski JQ, Lee VM (2000) Synucleins are developmentally expressed, and alpha-synuclein regulates the size of the presynaptic vesicular pool in primary hippocampal neurons. J Neurosci 20, 3214-3220.

[15] Lee HJ, Bae EJ, Lee SJ (2014) Extracellular $\alpha$--synuclein-a novel and crucial factor in Lewy body diseases. Nat Rev Neurol 10, 92-98.

[16] Burré J, Sharma M, Tsetsenis T, Buchman V, Etherton MR, Südhof TC (2010) Alpha-synuclein promotes SNARE-complex assembly in vivo and in vitro. Science 329, 1663-1667. 
[17] Jahn R, Fasshauer D (2012) Molecular machines governing exocytosis of synaptic vesicles. Nature 490, 201-207.

[18] Choi BK, Choi MG, Kim JY, Yang Y, Lai Y, Kweon DH, Lee NK, Shin YK (2013) Large $\alpha$-synuclein oligomers inhibit neuronal SNARE-mediated vesicle docking. Proc Natl Acad Sci U S A 110, 40874092.

[19] Han GA, Malintan NT, Collins BM, Meunier FA, Sugita S (2010) Munc18-1 as a key regulator of neurosecretion. J Neurochem 115, 1-10.

[20] Jorgacevski J, Potokar M, Grilc S, Kreft M, Liu W, Barclay JW, Bückers J, Medda R, Hell SW, Parpura V, Burgoyne RD, Zorec R (2011) Munc18-1 tuning of vesicle merger and fusion pore properties. J Neurosci 31, 9055-9066.

[21] Jacobs EH, Williams RJ, Francis PT (2006) Cyclin-dependent kinase 5, Munc18a and Munc18interacting protein 1/X11alpha protein up-regulation in Alzheimer's disease. Neuroscience 138, 511-522.

[22] Mukaetova-Ladinska EB, Andras A, Milne J, Abdel-All Z, Borr I, Jaros E, Perry RH, Honer WG, Cleghorn A, Doherty J, McIntosh G, Perry EK, Kalaria RN, McKeith IG (2013) Synaptic proteins and choline acetyltransferase loss in visual cortex in dementia with Lewy bodies. J Neuropathol Exp Neurol 72, 53-60.

[23] Vallortigara J, Rangarajan S, Whitfield D, Alghamdi A, Howlett D, Hortobágyi T, Johnson M, Attems J, Ballard C, Thomas A, O'Brien J, Aarsland D, Francis P (2014) Dynamin1 concentration in the prefrontal cortex is associated with cognitive impairment in Lewy body dementia. F100ORes 3, 108.

[24] Mukaetova-Ladinska EB, Garcia-Siera F, Hurt J, Gertz HJ, Xuereb JH, Hills R, Brayne C, Huppert FA, Paykel ES, McGee M, Jakes R, Honer WG, Harrington CR, Wischik CM (2000) Staging of cytoskeletal and beta-amyloid changes in human isocortex reveals biphasic synaptic protein response during progression of Alzheimer's disease. Am J Pathol 157, 623-636.

[25] Fuster JM (2001) The prefrontal cortex--an update: time is of the essence. Neuron 30, 319-333.

[26] Braak H, Alafuzoff I, Arzberger T, Kretzschmar H, Del Tredici K (2006) Staging of Alzheimer disease-associated neurofibrillary pathology using paraffin sections and immunocytochemistry. Acta Neuropathol 112, 389-404.

[27] Mirra SS, Heyman A, McKeel D, Sumi SM, Crain BJ, Brownlee LM, Vogel FS, Hughes JP, van Belle G, Berg L (1991) The Consortium to Establish a Registry for Alzheimer's Disease (CERAD). Part II. Standardization of the neuropathologic assessment of Alzheimer's disease. Neurology 41, 479486.

[28] Montine TJ, Phelps CH, Beach TG, Bigio EH, Cairns NJ, Dickson DW, Duyckaerts C, Frosch MP, Masliah E, Mirra SS, Nelson PT, Schneider JA, Thal DR, Trojanowski JQ, Vinters HV, Hyman BT, Aging Nlo, Association As (2012) National Institute on Aging-Alzheimer's Association guidelines for the neuropathologic assessment of Alzheimer's disease: a practical approach. Acta Neuropathol 123, 1-11.

[29] Thal DR, Rüb U, Orantes M, Braak H (2002) Phases of A beta-deposition in the human brain and its relevance for the development of AD. Neurology 58, 1791-1800.

[30] Folstein MF, Folstein SE, McHugh PR (1975) "Mini-mental state". A practical method for grading the cognitive state of patients for the clinician. J Psychiatr Res 12, 189-198.

[31] Whitfield DR, Vallortigara J, Alghamdi A, Howlett D, Hortobágyi T, Johnson M, Attems J, Newhouse S, Ballard C, Thomas AJ, O'Brien JT, Aarsland D, Francis PT (2014) Assessment of ZnT3 and PSD95 protein levels in Lewy body dementias and Alzheimer's disease: association with cognitive impairment. Neurobiol Aging. 
[32] Howlett DR, Whitfield D, Johnson M, Attems J, O'Brien JT, Aarsland D, Lai MK, Lee JH, Chen C, Ballard C, Hortobágyi T, Francis PT (2014) Regional Multiple Pathology Scores are Associated with Cognitive Decline in Lewy Body Dementias. Brain Pathol.

[33] Kirvell SL, Esiri M, Francis PT (2006) Down-regulation of vesicular glutamate transporters precedes cell loss and pathology in Alzheimer's disease. J Neurochem 98, 939-950.

[34] Whitfield DR, Vallortigara J, Alghamdi A, Hortobágyi T, Ballard C, Thomas AJ, O'Brien JT, Aarsland D, Francis PT (2014) Depression and Synaptic Zinc Regulation in Alzheimer Disease, Dementia with Lewy Bodies, and Parkinson Disease Dementia. Am J Geriatr Psychiatry.

[35] Vawter MP, Howard AL, Hyde TM, Kleinman JE, Freed WJ (1999) Alterations of hippocampal secreted N-CAM in bipolar disorder and synaptophysin in schizophrenia. Mol Psychiatry 4, 467475.

[36] Weiler R, Lassmann H, Fischer P, Jellinger K, Winkler H (1990) A high ratio of chromogranin A to synaptin/synaptophysin is a common feature of brains in Alzheimer and Pick disease. FEBS Lett 263, 337-339.

[37] Garcia-Reitbock P, Anichtchik O, Bellucci A, lovino M, Ballini C, Fineberg E, Ghetti B, Della CL, Spano P, Tofaris GK, Goedert M, Spillantini MG (2010) SNARE protein redistribution and synaptic failure in a transgenic mouse model of Parkinson's disease. Brain.

[38] Larsen KE, Schmitz Y, Troyer MD, Mosharov E, Dietrich P, Quazi AZ, Savalle M, Nemani V, Chaudhry FA, Edwards RH, Stefanis L, Sulzer D (2006) Alpha-synuclein overexpression in PC12 and chromaffin cells impairs catecholamine release by interfering with a late step in exocytosis. $J$ Neurosci 26, 11915-11922.

[39] Nakata Y, Yasuda T, Fukaya M, Yamamori S, Itakura M, Nihira T, Hayakawa H, Kawanami A, Kataoka M, Nagai M, Sakagami H, Takahashi M, Mizuno Y, Mochizuki H (2012) Accumulation of $\alpha$-synuclein triggered by presynaptic dysfunction. J Neurosci 32, 17186-17196.

[40] Burgoyne RD, Morgan A (2011) Chaperoning the SNAREs: a role in preventing neurodegeneration? Nat Cell Biol 13, 8-9.

[41] Orimo S, Uchihara T, Nakamura A, Mori F, Kakita A, Wakabayashi K, Takahashi H (2008) Axonal alpha-synuclein aggregates herald centripetal degeneration of cardiac sympathetic nerve in Parkinson's disease. Brain 131, 642-650.

[42] Minger SL, Honer WG, Esiri MM, McDonald B, Keene J, Nicoll JA, Carter J, Hope T, Francis PT (2001) Synaptic pathology in prefrontal cortex is present only with severe dementia in Alzheimer disease. J Neuropathol Exp Neurol 60, 929-936.

[43] Mukaetova-Ladinska EB, Xuereb JH, Garcia-Sierra F, Hurt J, Gertz HJ, Hills R, Brayne C, Huppert FA, Paykel ES, McGee MA, Jakes R, Honer WG, Harrington CR, Wischik CM (2009) Lewy body variant of Alzheimer's disease: selective neocortical loss of t-SNARE proteins and loss of MAP2 and alpha-synuclein in medial temporal lobe. ScientificWorldJournal 9, 1463-1475.

[44] Beyer K, Domingo-Sabat M, Ariza A (2009) Molecular pathology of Lewy body diseases. Int.J.Mol.Sci. 10, 724-745.

[45] Hynd MR, Lewohl JM, Scott HL, Dodd PR (2003) Biochemical and molecular studies using human autopsy brain tissue. J Neurochem 85, 543-562.

[46] Lewis DA (2002) The human brain revisited: opportunities and challenges in postmortem studies of psychiatric disorders. Neuropsychopharmacology 26, 143-154.

[47] Ferrer I, Martinez A, Boluda S, Parchi P, Barrachina M (2008) Brain banks: benefits, limitations and cautions concerning the use of post-mortem brain tissue for molecular studies. Cell Tissue Bank 9, 181-194.

[48] Crecelius A, Götz A, Arzberger T, Fröhlich T, Arnold GJ, Ferrer I, Kretzschmar HA (2008) Assessing quantitative post-mortem changes in the gray matter of the human frontal cortex proteome by 2-D DIGE. Proteomics 8, 1276-1291. 
Table 1. Summary of subjects' demographics. Values represent means \pm SEM. There were no significant differences (according to one-way ANOVA) between diagnostic groups for any of these variables. It has been demonstrated that most human brain proteins are quite stable with respect to postmortem factors and detailed analysis including large numbers of proteins covering the major cellular functions have not identified our proteins of interest as 'at risk' molecules being highly susceptible to postmortem changes [45-48]. DLB, dementia with Lewy bodies; PDD, Parkinson's disease dementia; AD, Alzheimer's disease

\begin{tabular}{|lcccc|}
\hline & Control & DLB & PDD & AD \\
\hline Number of cases & 24 & 50 & 33 & 16 \\
\hline Age of death & $80.4 \pm 1.4$ & $81.7 \pm 1.0$ & $79.8 \pm 1.1$ & $88.0 \pm 2.0$ \\
\hline Postmortem delay (h) & $37.1 \pm 6.4$ & $42.9 \pm 4.1$ & $33.4 \pm 2.9$ & $34.9 \pm 6.0$ \\
\hline Gender M/F (\%) & $58 / 42$ & $56 / 44$ & $53 / 47$ & $31 / 69$ \\
\hline Brain pH & $6.47 \pm 0.07$ & $6.52 \pm 0.04$ & $6.47 \pm 0.06$ & $6.30 \pm 0.08$ \\
\hline
\end{tabular}



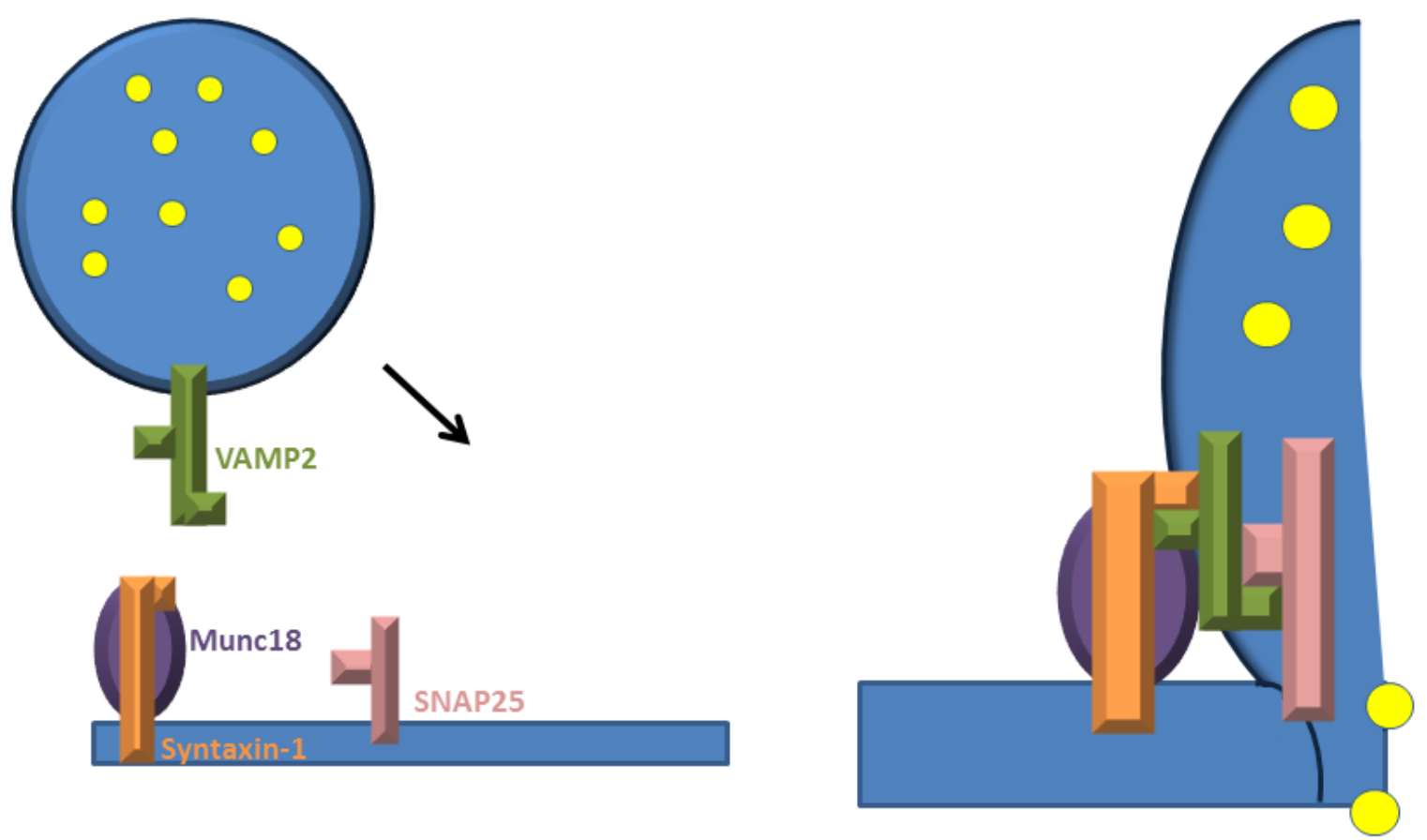

Figure 1. This diagram illustrates how the proteins of interest in this study interact to coordinate fusion of the synaptic vesicle and plasma membrane. Munc18 is bound to syntaxin-1 prior to vesicle docking. This allows a complex to form between VAMP2, SNAP25, and syntaxin-1, which results in vesicle docking. Monomeric $\alpha$-syn is not shown in this diagram as its putative role is in stabilizing the readily releasable pool of vesicles upstream of docking [17]. 

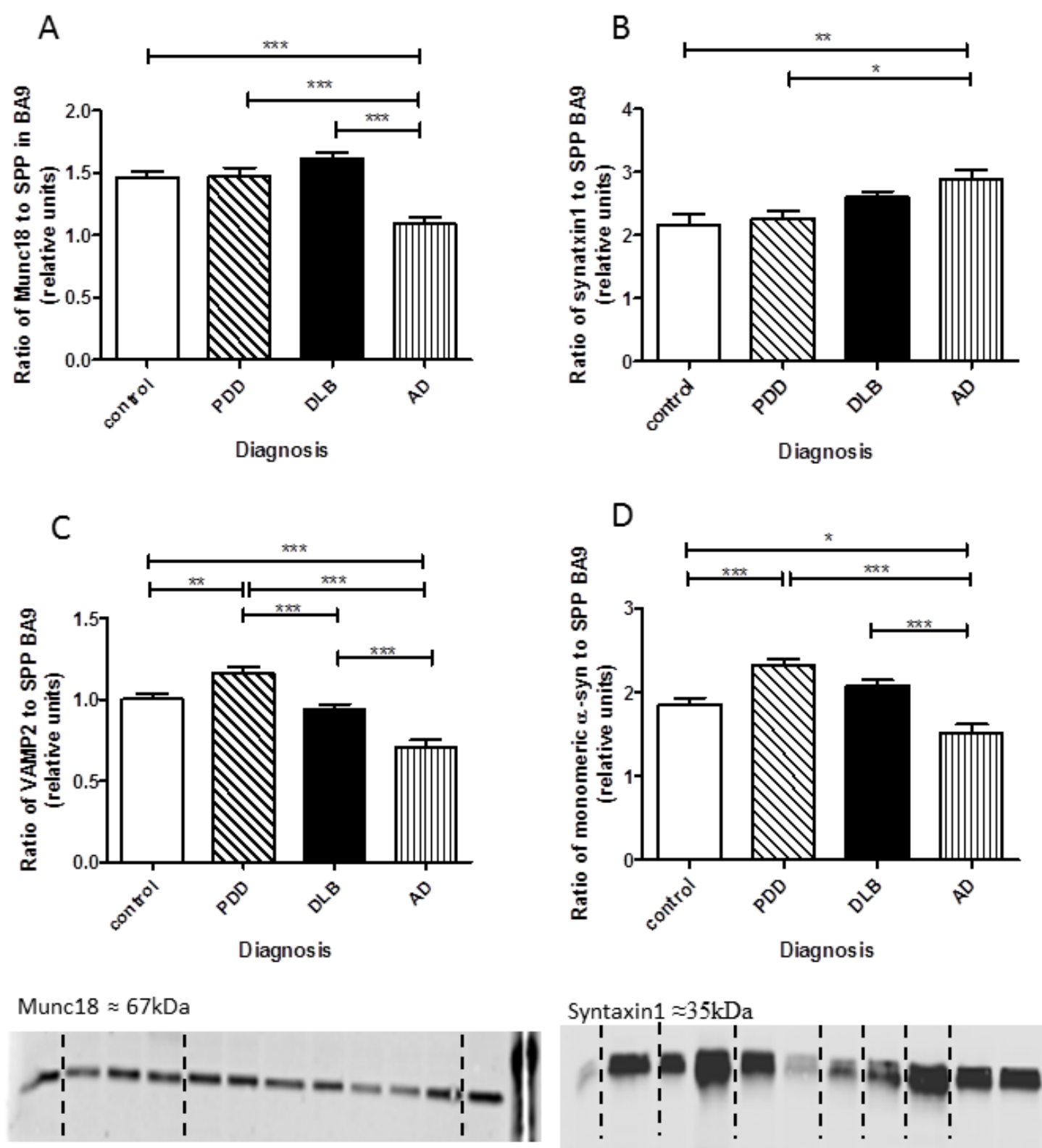

Rat, control, PDD, Rat

Rat, control, DLB, control, DLB, AD, Control, AD, Rat

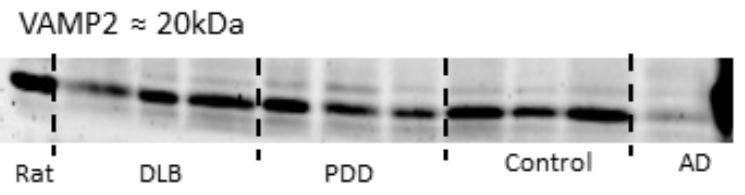

monomeric $\alpha$-Synuclein $\approx 19 \mathrm{kDa}$

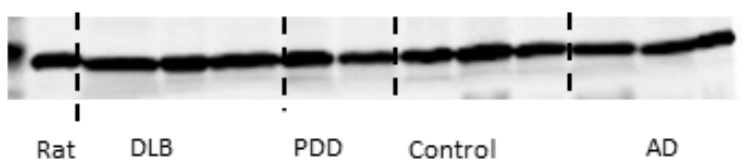


Figure 2. Synaptic proteins of interest expressed as a ratio to synaptophysin (SPP) and grouped according to clinical diagnosis. One-way ANOVA and Bonferroni post-hoc tests were used to determine the differences in the protein ratios between diagnostic groups. A) Munc18: $n=23,30$, 37, 16. $\mathrm{F}=(3,102) 11.995, \mathrm{p}=0.000001$. Bonferroni post-hoc tests showed AD cases to be significantly higher than: control $p=0.001$, PDD $p=0.000273$, and DLB $p<0.000001$. B) Syntaxin1: $n=23,31,37,16 . F(3,103) 5.128, p=0.002$. Bonferroni post-hoc tests showed AD cases to be significantly higher than control $p=0.007$ and PDD $p=0.017$. C) VAMP2: $n=19,24$, 29, 15. $\mathrm{F}=(3,83) 25.814, \mathrm{p}<0.000001$. Bonferroni post-hoc tests showed; PDD cases to be significantly higher than control $\mathrm{p}=0.01, \mathrm{DLB} p=0.000019$, and $\mathrm{AD}$ cases $\mathrm{p}<0.000001$. Furthermore AD cases were significantly lower than control $p=0.000004$ and DLB cases $\mathrm{p}=0.000073$. D) Mon $\alpha$-syn: $\mathrm{n}=19,24,28,15 . \mathrm{F}(3,82) 16.621, \mathrm{p}<0.000001$. Bonferroni PDD to control $p=0.000463$. AD to control $p=0.049$, PDD $p<0.000001$, and DLB $p=0.000027$. The vertical bars represent means with SEM. 
Figure 3. Associations between the monomeric $\alpha$-synuclein:synaptophysin $(\alpha$-syn/SPP) ratio and the duration of dementia and parkinsonism.
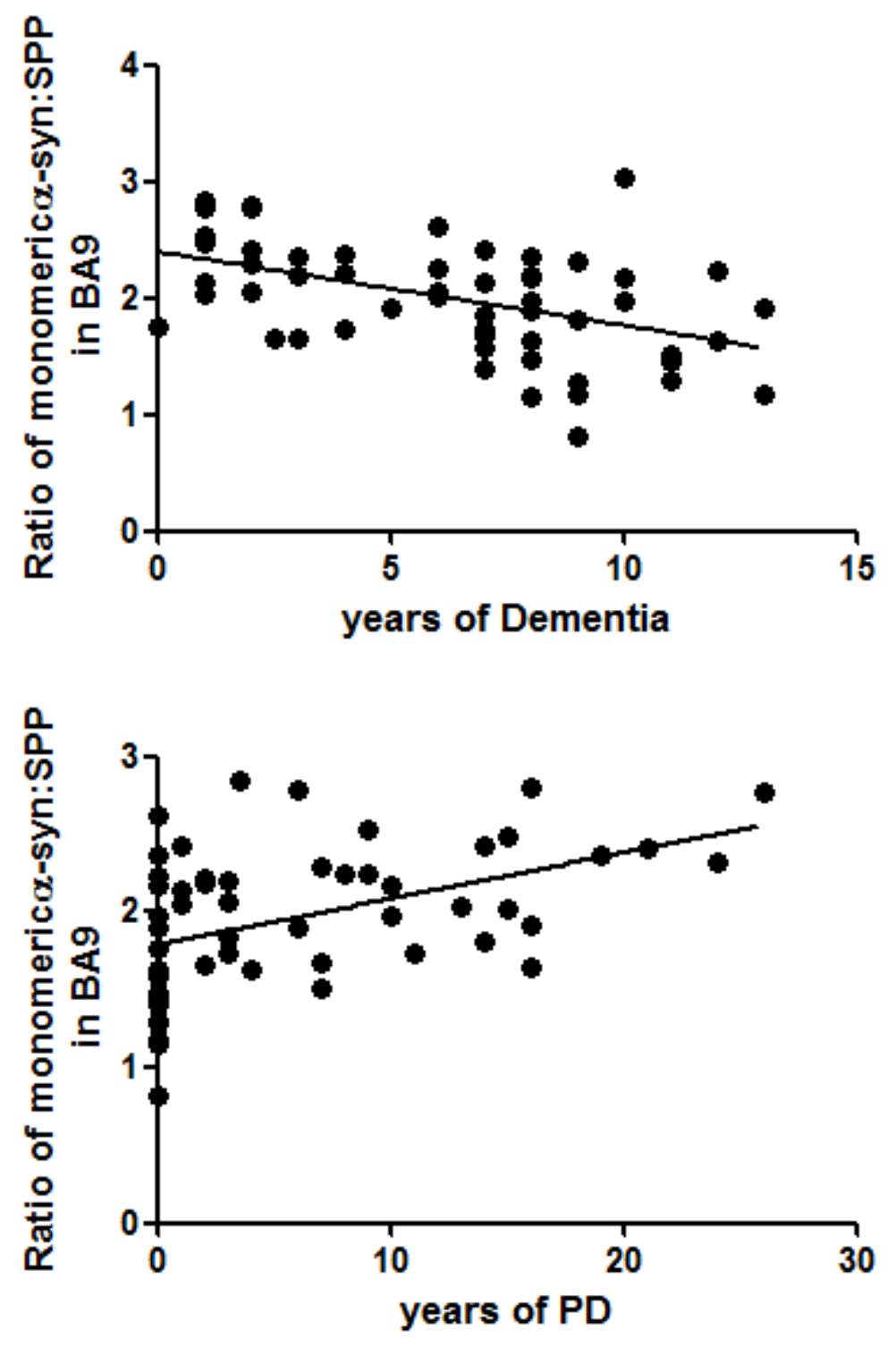

Linear Regression analysis showed the years of dementia and of parkinsonism to be predictors of the ratio of monomeric $\alpha$-syn to SPP in BA9. $\mathrm{R}^{2}=0.399 . \mathrm{SE}=0.371664$. Years of dementia: $\mathrm{B}=-$ 
0.06, $\mathrm{SE}=0.015, \mathrm{t}=-4.034, \mathrm{p}=0.000188$. Years of $\mathrm{PD}: \mathrm{B}=0.21, \mathrm{SE}=0.008, \mathrm{t}=2.801, \mathrm{p}=0.007$. ANOVA: $\mathrm{F}=(2,50) 16.599, \mathrm{p}=0.000003$. 
Figure 4. Associations between the VAMP2:synaptophysin ratio and the duration of dementia and parkinsonism.
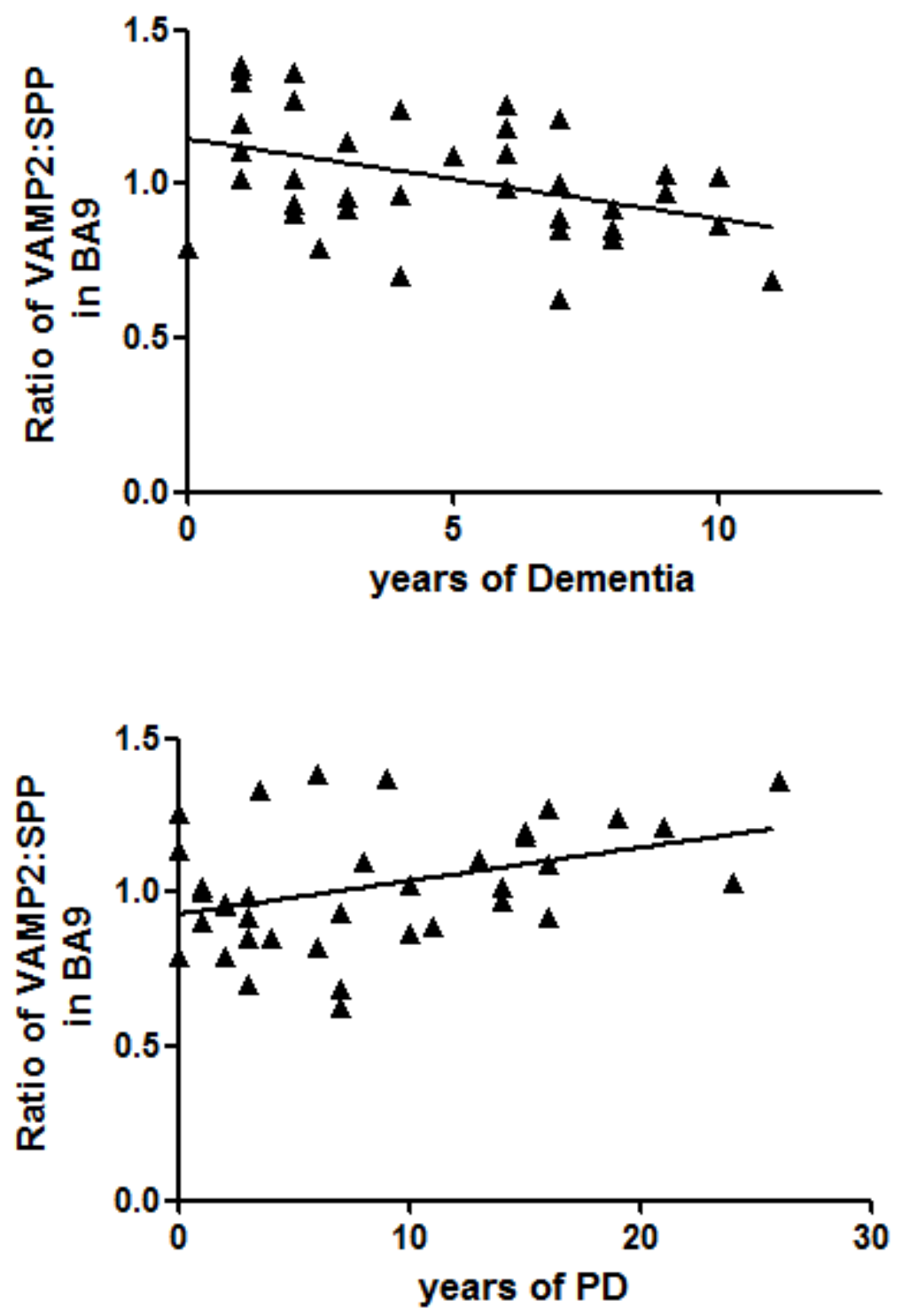

Linear Regression analysis showed the years of dementia and of parkinsonism to be predictors of the ratio of VAMP2 to SPP. $\mathrm{R}^{2}=0.463 . \mathrm{SE}=0.17939$. Years of dementia: $\mathrm{B}=-0.028, \mathrm{SE}=0.007$, $\mathrm{t}=-3.833, \mathrm{p}=0.000355$. Years of $\mathrm{PD}: \mathrm{B}=0.15, \mathrm{SE}=0.004, \mathrm{t}=4.032, \mathrm{p}=0.000189$. ANOVA: $\mathrm{F}=(2,50) 21.595, \mathrm{p}<0.000001$. 
Figure 5. $\alpha$-synuclein pathology grouped by clinical diagnosis.

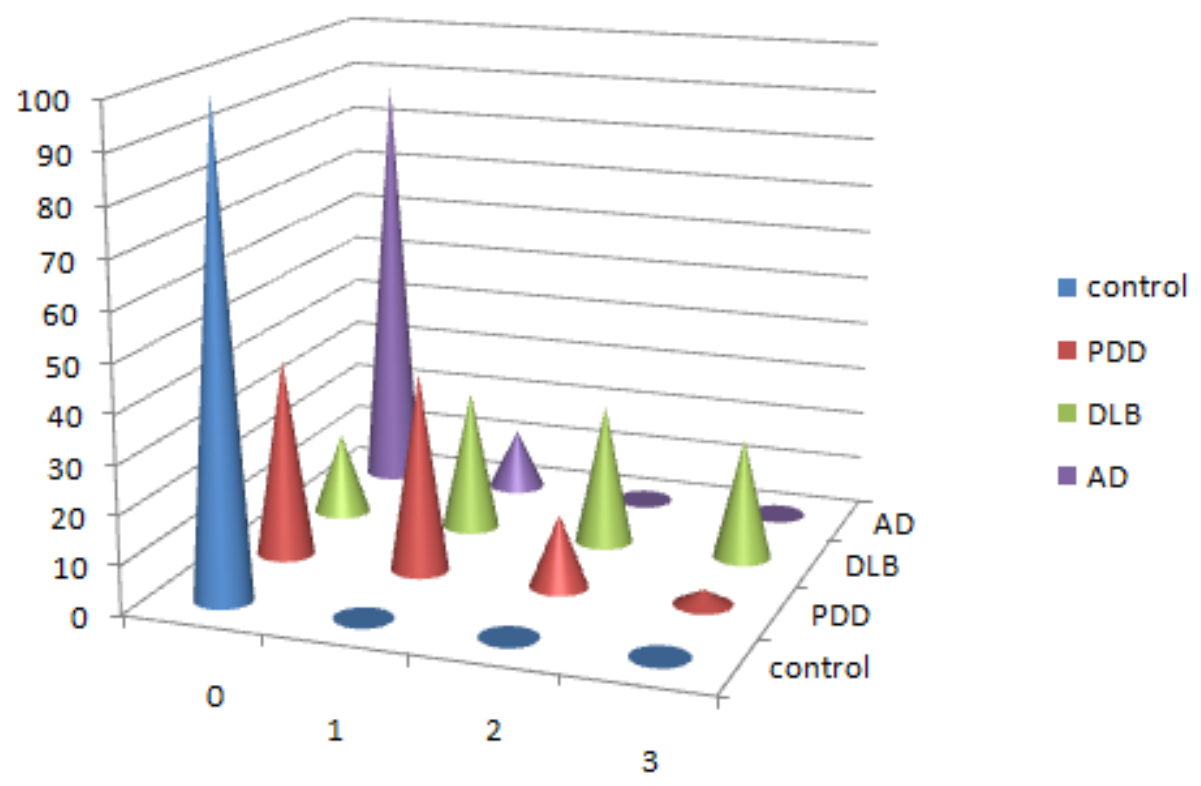

The percentage of cases in each of the categories of $\alpha$-synuclein pathology score $(0=$ absent, $1=$ sparse, 2 = moderate, $3=$ severe/frequent) according to clinical diagnosis. 